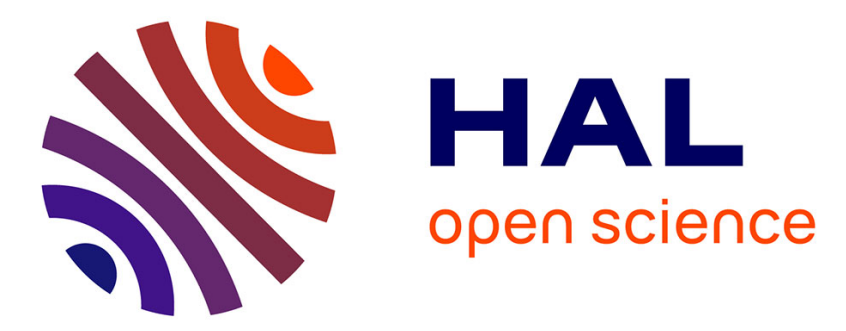

\title{
Results from a one dimensional code for simulating the ductile break-up process of shaped charge jets and expanding rings
}

\author{
E. Hirsch, A. Magen
}

\section{- To cite this version:}

E. Hirsch, A. Magen. Results from a one dimensional code for simulating the ductile break-up process of shaped charge jets and expanding rings. Journal de Physique IV Proceedings, 1994, 04 (C8), pp.C8-589-C8-594. 10.1051/jp4:1994892 . jpa-00253453

HAL Id: jpa-00253453

https://hal.science/jpa-00253453

Submitted on 1 Jan 1994

HAL is a multi-disciplinary open access archive for the deposit and dissemination of scientific research documents, whether they are published or not. The documents may come from teaching and research institutions in France or abroad, or from public or private research centers.
L'archive ouverte pluridisciplinaire HAL, est destinée au dépôt et à la diffusion de documents scientifiques de niveau recherche, publiés ou non, émanant des établissements d'enseignement et de recherche français ou étrangers, des laboratoires publics ou privés. 


\title{
Results from a one dimensional code for simulating the ductile break-up process of shaped charge jets and expanding rings
}

E. Hirsch and A. Magen

Mil, P.O. Box 02128, I.D.F. Israel

\begin{abstract}
Resume
Le code (decrit en detail dans la Ref. 1) a pour but de simuler le procede de localisation et de cassure du jet de charge creuse ainsi que l'expansion des anneaux, suivant la formation macroscopique des bandes de cisaillement.

Le modele d'elongation decrit, est forme de blocs de masses de differentes tailles, chacune etant separee par des bandes de cisaillement $g l$ issantes comportant des efforts de rupture variants (Fig. $1 \mathrm{a}, \mathrm{b}$ ). La simulation citee plus haut est basee sur la resolution des equations de Mouvement du systeme general.

Les principaux resultats d'essais de simulation sont ici presentes. Les resultats indiquent que la valeur moyenne de l'effort de rupture, ne varie pas jusqu'a la cassure du jet, ceci malgre le dispersion de sa valeur a l'interieure des bandes de cisaillement. la prediction du nombre de fragments en fonction de l'elongation, a partir du modele d'expansion des anneaux de cuivre, reproduit d'une maniere etonante les mesures experimentales quand les parametres de Johnson-Cook sont introduits.
\end{abstract}

\section{Abstract}

The code (described in detail in Ref. 1) simulates the localization and break-up process of shaped-charge jets and expanding-rings, following macroscopic shear bands formation.

The elongating specimen is described as consisting of different size mass-blocks separated by sliding shear-bands with varying yield stress (see Fig. 1a,b.) and the simulation is based on solving the equations of motion for the whole system.

The main results of the simulation runs are presented. They indicate that although the yield stress value inside shear bands' is very widely spread its average value remains unchanged till break-up. The predicted number of fragments as a function of the strain rate for expanding copper rings is found to be in excellent agreement with the experimental measurements when the Johnson-Cook parameters are used.

\section{BACKGROUND}

In the final stage of shaped charge jet break-up, planar macroscopic shear bands form at 45 degrees to the jet elongation 
direction. This was observed and explained in Ref. 2. Within a typical time period of few microseconds, most of the formed shear bands stop sliding while the slide velocity of those remaining in motion increases. When the average slide velocity component in the elongation direction becomes equal to the average velocity difference between neighboring fragments, denoted as $V p l$ in accordance with Ref. 3 (see also Ref. 4) the specimen breaks by separation of those shear bands sides which remain sliding, via their slipping out of contact.

\section{Code development}

In order to study this final stage on a quantitative basis the computer code described in Ref. 1 was written, for simulating the process occurring in the material since the macroscopic shear bands are formed till it breaks into fragments. In this code, the specimen is described as an array of mass blocks of random size, the ends of each mass block comprising the banks of two neighboring shear bands. See Fig. 1 a for the definition and notation in a ring configuration and Fig. $1 \mathrm{~b}$ for the jet configuration. (Note that $M(0)$ and $M(N)$ are identical).

The equations of motion of the whole system were solved, using a special algorithm, for many examples of given yield force values for the individual shear-bands, for many velocity difference values (VO) between the specimen ends, for many assumed numbers of participating mass blocks and for many length over initial diameter (L/DIN) ratios of the whole specimen.

The yield strength between neighboring mass blocks and the mass blocks inertia are the only forces participating in the simulated process. Therefore, once the specimen's dimensions, number of blocks, their mass variation and vo are specified the elongation and break-up process depends merely on the evolution of the shear bands yield force, $F(J)$, which is equal to the yield strength times the initial area (AIN) times the fraction of shear band area which is still in contact, EPS(J). This fraction is a function of the specimen's diameter at the moment of macroscopic shear-bands formation (DIN) and the individual shearband displacement, $\mathrm{X}(\mathrm{J})$. Due to the 45 degrees angle between the shear bands and elongation direction we approximately have:

$$
\operatorname{EPS}(\mathrm{J})=\mathrm{X}(\mathrm{J}) / \mathrm{DIN}
$$

\section{The Equations of Motion}

Let's examine an elongating specimen with two sliding shearbands. The average slide velocity is equal to $\mathrm{vo} / 2$. The difference in the impulse between the right and left sides of the block $M(1),\{F(2)-F(1)\} * d t$ must be equal to the change in the momentum of this black: $M(1) * d\{V(1)-V(2)\}$.

Denoting: $\{F(2)-F(1)\} / M(1)=a(1)$, we get the equation:

$$
d\{V(1)-V(2)\}=a(1) * d t
$$

which is subject to the constraint:

$$
\mathrm{V}(1)+\mathrm{V}(2)=\mathrm{VO}
$$

Substituting this constraint into $\mathrm{Eq} .2$, we get and

$$
\mathrm{d}\{\mathrm{V}(1)-\mathrm{VO} / 2\}=\mathrm{a}(1) * \mathrm{~d} t / 2=\{F(1)-[F(1)+F(2)] / 2\} / M(1) * d t
$$

$d\{V(2)-V 0 / 2\}=-a(1) * d t / 2=\{F(2)-[F(1)+F(2)] / 2\} / M(1) * d t$

which represents a one degree of freedom set of equations because, by summing the equations, we get zero on each hand.

It can be shown that when Eqs. 3 are generalized to $N$ sliding shear-bands, they produce the following general form: 


$$
d\{V(J)-V O / N\}=\left\{\sum_{I=1}^{J-1}-I * a(I)+\sum_{I=J}^{N-1}(N-I) * a(I)\right\} / N * d t
$$

The loss of kinetic energy to the energy dissipated by deformation in the entire elongating specimen is used in the code to reduce vo (unless it is intentionally kept constant) at the end of each calculation cycle ( $t$ ime step).

4. Algorithm for equations of motion solution

Denoting the sums over index I on the right hand of

Eqs. 4 as $A(J)$ these equations reduce to:

$$
\mathrm{d}\{\mathrm{V}(\mathrm{J})-\mathrm{VO} / \mathrm{N}\}=\mathrm{A}(\mathrm{J}) * \mathrm{dt}
$$

This form allows us to find the time (dt) required by each shear-band to stop sliding under the assumption that $A(J)$ can be represented by a constant during the cycle:

$$
\mathrm{dt}=-\mathrm{VO} / \mathrm{N} / \mathrm{A}(\mathrm{J})
$$

If $d t$ is negative, it means that this shear-band is accelerating during the current cycle and if it is positive then the specific shear-band slows, tending to stop sliding. Among those dt time increments which are positive, however, we choose the smallest, denoted as DTM. This way, we obtain a time step which is exactly equal to the time increment needed to let the next shear-band stop sliding. This time increment also is usually small enough to justify the assumption that $A(J)$ is constant during the cycle.

Having found DTM, we substitute it into EqS. 5 producing the new $V(J)$ and additional displacement values: $V(J) * D T M$.

We keep the values of velocity and total displacement from the former cycle in memory in order to use them to find the new total displacement $X(J)$ at each shear-band as well as the corresponding individual deformation, given by $\mathrm{Eq} .1$. We also use it to find the deformation energy $D E(J)$ and the power $D E(J) / D T M$ generated in each shear-band during the cycle as well as their corresponding averages over all the shear-bands. The new values of EPS(J) and $D E(J) / D T M$ may then be used to update the yield force $F(J)$ for the next cycle, by taking into account the softening caused by the heat $D E(J)$.

At the end of each cycle the two neighboring blocks the shear band between which stopped sliding become one block the mass of which is equal to the sum of their masses, and the total number of blocks and sliding shear bands reduces by one. This process continues cycle by cycle until break-up is reached.

\section{Reaching break-up}

Break-up is reached whenever the force between the sides of a shear-band vanishes. This occurs either due to separation of shear bands' sides by sliding out of contact (necking) i.e, when EPS $(J)$ becomes larger than unity, or due to reduction of the yield stress to zero when the Bernoulli term $\frac{1}{2}^{*} R^{2}$ *VI $^{\wedge} 2$, where Vs is the slide velocity, becomes larger than the yield stress oy thus nuliffying the adhesion force. (The Bernoulli term is only effective whenever specimen having a small L/DIN are run, i.e, not in the practically used expanding rings).

\section{Main results}

By applying the postulate that the deformation mechanism parameters must minimize the energy absorbed in plastic deformation during specimen inertial elongation, it is found by means of the computer simulations that the yield stress in the 
macroscopic shear-bands, following the instart of their formation, is very widely spread. It means that the deformation energy dissipated since macroscopic shear-bands were formed

until break-up is reached, is minimum when the yield stress (oy) in individual shear-bands is randomly distributed.

The average oy value during the process, simulated as explained above, shown in Fig. 2 a as a function of the cycle number and in $F i g .2 b$ as $a$ function of time, is found to be constant within the statistical fluctuations.

When the Johnson and cook equation of state parameters for OFHC copper are applied [5], to predict the number of fragments formed by the copper expanding rings' measurements reported in Ref. 9, an excellent agreement is found (Fig. 3). The simulations were run estimating that macroscopic shear bands formation occurs at $46 \%$ out of the $51 \%$ final elongation [7,8] (The results are insensitive to the exact value of this number).

By fitting a straight line going through the origin, the following relation is found to hold between the final number of fragments NS the expansion velocity (Vr) times $2^{*} \pi$ and the average yield stress (oyave):

$$
\text { oyave }=4 * \sqrt{2} * \text { Rho * Vpl }{ }^{2}
$$

where Rho is the material mass density and Vpl is the average value of $2 * \pi * V r / N S$. However, the simulation follows the experimental results without any fitting of parameters.

This agreement makes it possible to use either the approximation of Eq. 7 or the simulation code itself, to relate the material yield stress, prior to macroscopic shear-bands formation, to the number of fragments formed. Equation 7 was successfully used in Ref. 6 to model the shaped-charge

jet elongation and break-up process in detail, getting a good agreement with shaped-charge jet break-up time measurements.

The correlation factor ( $r$ ) between the velocity and displacement of the individual shear bands is shown in Figs. 2a and $2 b$ as a function of the cycle number and time respectively. This parameter reveals that the localization into finally breaking shear-bands proceeds in cycles (see Ref. 7) which are of chaotic characteristic. A drop in $r$ occurs when too many of the slowing down shear bands already stopped sliding and many of those which have so far accelerated must change their sliding direction. This example indicates that many more details can probably be studied by means of the code in the future.

\section{References}

[1] Hirsch, E. and Magen, A. "Simulation of Shaped-Charge Jet and Expanding-Ring Break-up Process Using a One-Dimensional Model". Propellants, Explosives, Pyrotechnics (In process of publication).

[2] E. Hirsch, Propellants, Explosives, Pyrotechnics. $17,27-33$.

[3] E. Hirsch. Propellants and Explosives. 4,89-94 (1979).

[4] F. Jamet, "Investigation of Shaped Charge Jets Using Flash X-Ray Diffraction". Proceedings of the Eighth International Symposium on Ballistics, Orlando, Florida, Oct. 23 - 25 (1984). [5] G.R. Johnson and W.H.Cook," A Constitutive Model and Data for Metals Subjected to Large Strains, Large Strain Rates and High Temperatures". Proceedings of the 7th International symposium on Baliistics. The Hague, The Netherlands, April 19-21, 1983.

[6] Hirsch, E., "How does the Shaped Charge Jet Become Hollow?" Proceedings of the 14th International Symposium on Ballistics, 
Sep. 26-29, 1993, Quebec Hilton, Quebec, Canada.

[7] E. Hirsch, Propellants, Explosives, Pyrotechnics, 15, $166-176$ (1990).

[8] I. Gilath, "High Strain Rate Ductility of Aluminum in Uniaxial Tension as an Effect of Laser Induced Shock Waves". Impact loading and Dynamic Behavior of Materials. Vol 2, 669-676. DCM. Informationsgesel lschaft. Verlag. (1988).

[9] Grady, D.E., Kipp,M.E. and Benson, D.A., "Energy and Statistical Effects in Dynamic Fragmentation of Metal Rings". Ins. Phys. Conf. Ser. No.70. (Oxford 1984).

[10] Hirsch, E., Propellants, Explosives, Pyrotechnics 14, 31-38 (1989).

Acknowledgement

The authors wish to express their deep gratitude to Prof. Sol R. Bodner of the Haifa Technion, Israel Institute of Technology for illuminating comments and very fruitful discussions.

Many thanks are due to Dr. Norbert Burman of DSTO, Material Research Lab. Ascot Vale, Australia, for the very fruitful discussions held during the 13 th and $14 \mathrm{th}$ International Symposia on Ballistics.

Deep gratitude is expressed to Joseph $\mathbf{E}$. Backofen $\mathrm{Jr}$. of the BRIGS Company for illuminating comments and for editing the original paper manuscript.

Fig. 1a

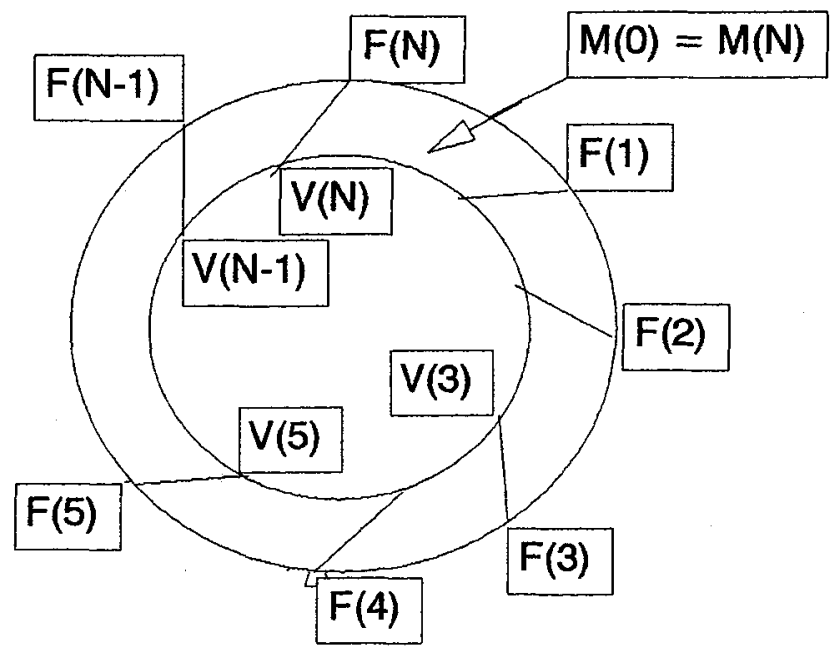

Fig. 1b

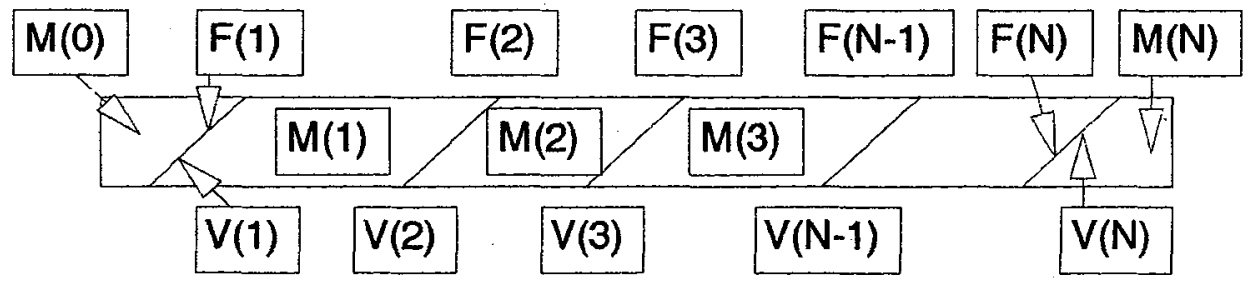




\section{$X, V$ Correlation and Ave. Yield stress}

96 Mass-Blocks;2* $\mathrm{Pi}{ }^{*} \mathrm{Vr}=395 \mathrm{~m} / \mathrm{sec}$;Co.Ring
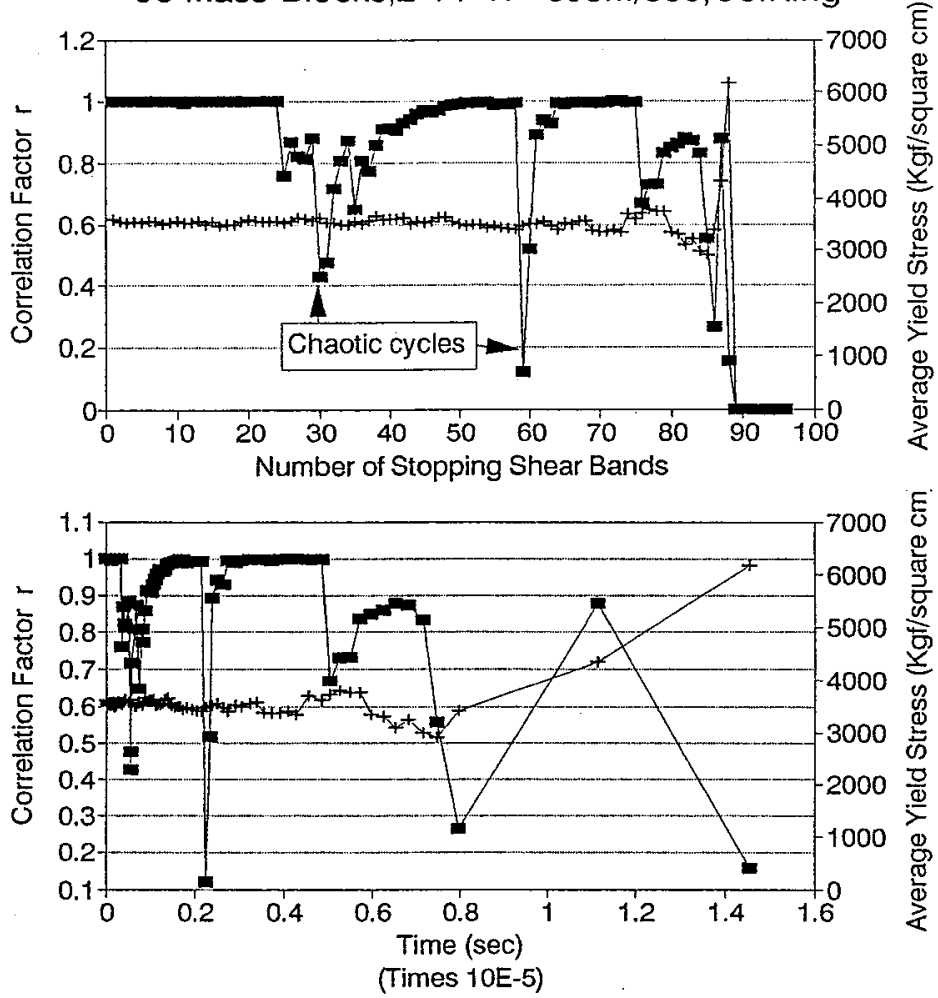

Fig. $2 a, b \quad \rightarrow-r$-factor $\rightarrow$ Yield stress

Fig. 3 - Copper Rings Break-up

$2^{*} i^{\star}$ Rad Velocity Vs. No. of Fragments

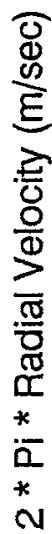

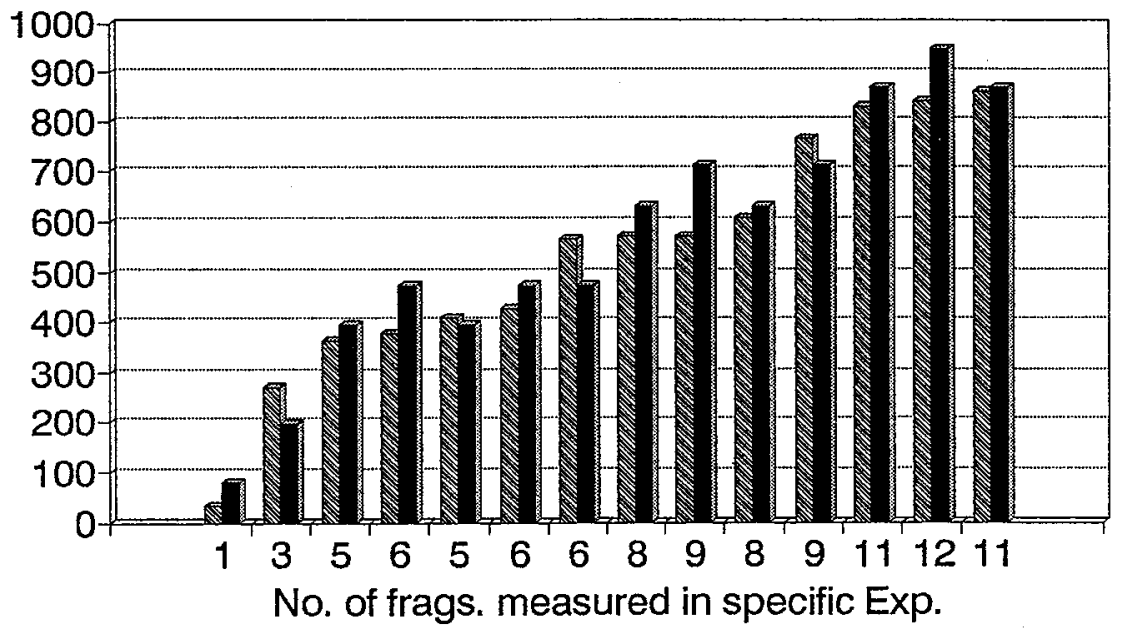

